\title{
Información Tecnológica
}

\section{EN SÍNTESIS}

1. Listado de artículos en Información Tecnológica, volumen 33, número 1, 2022 (Pág. 1-2)

\section{ARTÍ́CULOS}

2. La gestión del conocimiento en la auditoría interna: un modelo teórico-relacional para el crecimiento empresarial. Claudia L. Serrano, Raúl I. Cruz, Jesús Salcedo y Alexandra C. Malagón (Colombia). (Pág. 3-10)

3. Programación multiobjetivo de quirófanos considerando el bienestar del cliente interno y externo. Milton A. Londoño, Cristiam A. Gil, Juan S. Mock kow y Juan P. Orejuela (Colombia). (Pág. 11-24)

4. Análisis de las relaciones internacionales del Ecuador con la Comunidad Andina de Naciones (CAN) para determinar su efecto en el flujo del comercio internacional de la región. César E. Freire, Félix M. Carrera, Gabriela E. Hurtado y Jessica S. Matute (Ecuador). (Pág. 25-34)

5. Formulación de una estrategia para el control puntual de un contaminante y su implementación usando cómputo paralelo. Daniel Peña-Maciel, David Parra-Guevara y Yuri N. Skiba (México). (Pág. 35-48)

6. Relaciones entre las fases del proceso de gestión del conocimiento en unidades académicas. Emilio R. RodríguezPonce, Liliana M. Pedraja-Rejas, Carmen A. Araneda-Guirriman y Camila P. Muñoz-Fritis (Chile). (Pág. 49-56)

7. Efecto de la preparación fría de café (Coffea arabica L. var. Castillo) sobre la capacidad antioxidante y la calidad sensorial. Angela M. Ormaza-Zapata, Félix O. Díaz-Arango y Benjamín A. Rojano (Colombia). (Pág. 57-70)

8. Condiciones facilitadoras para el desarrollo del emprendimiento: una mirada al caribe colombiano. Karelis Del C. Barrios-Hernández, Brenda C. Figueroa-Saumet, María J. Niebles-Bárcenas, y Robinson De J. Palacio-Pérez (Colombia). (Pág. 71-80)

9. Alfabetización financiera en jóvenes en Ecuador: modelo de medición y sus factores determinantes. Carola L. MenaCampoverde (Ecuador). (Pág. 81-90)

10. Combinación de alta cizalla y ultrasonido para la obtención de nanopartículas de carbonato de calcio a partir de cáscara de huevo. Luz M. Gómez-Alvarez, Freimar Segura-Sánchez y José E. Zapata (Colombia). (Pág. 91-106)

11. La percepción del alumnado de sexto grado de educación primaria hacia las personas que se encuentran en situación de discapacidad: la escala EPADI-1. Yonatan Díaz Santa María y Jesús Molina Saorín (España).

(Pág. 107-120)

12. Aplicación de la p-mediana y ruteo de vehículos para la reducción de distancias en una empresa de servicio postal. David E. Sánchez y Eduardo Gutiérrez (México). (Pág. 121-130)

13. Internacionalización de la empresa familiar: un modelo prospectivo. Jenny Romero-Borre, Lissette HernándezFernández, Rafael Portillo-Medina (Colombia), Ana Hernández-Chacín (Venezuela). (Pág. 131-144)

14. Localización de equipamientos para el registro de automotores y conductores a partir de un análisis de accesibilidad integral: caso de estudio Bogotá, Colombia. Diego A. Escobar, Jorge A. Montoya y Carlos, A. Moncada (Colombia). (Pág. 145-156)

15. Percepción del teletrabajo de directivos y supervisores de empresas de la Región del Maule (Chile) en tiempos de la pandemia COVID-19. Miguel A. Bustamante, Roberto M. Campos (Chile) y María del C. Lapo (Ecuador).

(Pág. 157-168)

16. Relevancia de los resultados de pruebas de laboratorio para predecir la recuperación de hierro a nivel industrial. Luis I. Valderrama, Oscar I. Herrera y Ana M. Rivera (Chile). (Pág. 169-180)

17. Análisis termográfico de un motor de encendido provocado, inducido a fallas mediante la aplicación de diseño de experimentos (DoE). Rubén Carrion-Jaura, Jairo Castillo-Calderón, Diego Díaz-Sinche, Bryan Briceño-Martínez (Ecuador). (Pág. 181-192)

18. Producción de briquetas a partir de raquis residual de la palma africana para las comunidades alfareras del norte del Cesar (Colombia). Marlon Bastidas-Barranco, Robert Valera-Restrepo y Dario Serrano-Florez (Colombia).

(Pág. 193-202) 
19. Efecto del tratamiento térmico en la estabilidad de geles obtenidos a partir de harinas de quinua. Yesika B. Lopez, Diego F. Roa y Jesús E. Bravo (Colombia). (Pág. 203-214)

20. Rendimiento de bombas de calor con ciclo de compresión de simple etapa y ciclo de compresión de doble etapa con inyección de vapor para producción de agua caliente sanitaria. Fernando M. Tello-Oquendo, Bryan A. LópezRomero, Daniela C. Vásconez-Núñez y Gloria E. Miño-Cascante (Ecuador). (Pág. 215-224)

21. Modelo de crecimiento microbiano para predecir el comportamiento de Salmonella spp. en queso costeño colombiano. Rafael E. González, Arnulfo Tarón Dunoyer y Jaime Pérez Mendoza (Colombia). (Pág. 225-234)

22. Biocompuesto bicapa incorporado con nisina: caracterización y eficacia contra Escherichia coli. Karen. S. MuñozPabon, Carlos A. González-Callejas, y Héctor. S. Villada-Castillo (Colombia). (Pág. 235-244)

23 Gestión de riesgos operacionales en cadenas de suministro agroalimentarias bajo un enfoque de manufactura esbelta. Andrés M. Paredes-Rodriguez, Vivian L. Chud-Pantoja y Claudia C. Peña-Montoya (Colombia). (Pág. 245-258)

24. Clasificación de pan Francés según sus propiedades fisicoquímicas mediante la aplicación de los análisis de conglomerados y discriminante. Carlos A. Suca-Apaza, Fernando Suca-Apaza y Diana C. Rojas (Perú). (Pág. 259-270)

25. Desarrollo de aplicación móvil para niños con dificultades de aprendizaje de la lectura y escritura. Carlos MáñezCarvajal y Jose Francisco Cervera-Mérida (España). (Pág. 271-278)

26. Eficacia de biofungicidas para el manejo de la costra negra (Rhizoctonia solani Kühn) de la papa en Nariño, Colombia. Carlos A. Betancourth, Benjamín A. Sañudo, Carlos A. Flórez y Claudia E. Salazar (Colombia).

(Pág. 279-288) 